\title{
Aberrant methylation of miR-125b1 in gastric cancer: A case-control study
}

\author{
M. RAAD ${ }^{1}$, Z. SALEHI ${ }^{1, *}$, S. T. SASANI ${ }^{1}$, F. MASHAYEKHI ${ }^{1}$, K. AMINIAN ${ }^{2}$, M. H. KOUTENAYI ${ }^{3}$
}

${ }^{1}$ Department of Biology, Faculty of Sciences, University of Guilan, Rasht, Iran; ${ }^{2}$ Gastrointestinal and Liver Diseases Research Center, Razi Hospital, Guilan University of Medical Sciences, Rasht, Iran; ${ }^{3}$ Student Research Committee and Pharmaceutical Sciences Research Center, Mazandaran University of Medical Sciences, Sari, Iran

${ }^{*}$ Correspondence: geneticzs@yahoo.co.uk

Received September 26, 2018 / Accepted January 8, 2019

\begin{abstract}
Gastric cancer (GC) is a complex heterogeneous process and the molecular mechanisms underlying its initiation or propagation are still not very well characterized. Aberrant gene expressions are key features of cancer. DNA methylation in a promoter region is an important epigenetic mechanism for the gene silencing. Here, the impact of DNA methylation in regulating the expression of miR-125b1 is explored. A total of 285 genetically unrelated subjects including 175 healthy controls and a total of 110 GC patients participated in this study. We performed nested methylation-specific polymerase chain reaction (MS-PCR) to evaluate methylation pattern of miR-125b1 promoter and quantitative real-time polymerase chain reaction (qRT-PCR) to determine the RNA expression changes in GC and normal tissues. The frequency of methylated allele was $24.5 \%$ in GC cases but only $10 \%$ in normal tissues. Statistically significant correlation between CpG dinucleotide methylation of miR-125b1 promoter and increased risk of gastric adenocarcinoma was observed (OR=2.57; 95\%CI $1.60-4.13 ; \mathrm{p}=0.0001)$. In addition, miR-125b1 promoter methylation correlated with tumor location and stages. Expression of miR-125b1 was much higher in normal tissue compared to cancerous tissue. However, methylation status of the miR-125b1 promoter was not correlated with miR-125b1 expression in cancerous specimens $(\mathrm{p}<0.05)$. In conclusion, this is a first report of miR-125b1 promoter methylation in GC. More research is needed to fully elucidate the underlying molecular mechanisms of GC susceptibility.
\end{abstract}

Key words: gastric cancer, promoter methylation, miR-125b1, epigenetics, gene expression

GC is the fourth most common cancer and the second leading cause of cancer related death in the world. More than 950,000 new cases of GC are diagnosed and approximately 720,000 deaths are reported worldwide every year [1]. It is a complex, multifactorial disease with a strong interplay between genetic and environmental factors. H. pylori, EBV, salt preserved foods, alcohol and smoking are the major risk factors [2]. Although the exact molecular pathology of GC is not clear, it has been shown that dysregulation of some microRNAs (miRNAs) is associated with the development and progression of GC [3-5].

MicroRNA is a small non-coding RNA molecule containing about 22 nucleotides involved in RNA silencing and post-transcriptional regulation of gene expression. Thus play critical roles in many biological processes such as proliferation, differentiation, apoptosis and even carcinogenesis [6, 7]. One of these important microRNAs is miR-125b. Several studies have been conducted on the expression of miR-125b in gastric carcinoma tissues in comparison with normal gastric tissues to show the miR-125b deregulation in GC $[8,9]$. However, the mechanism of the aberrant expression of miR-125b in gastric carcinoma tissues is still unknown. MiR-125b is transcribed from two genomic loci (miR-125b1 (11q24.1) and miR-125b2 (21q21.1)). These two loci produce different hairpin precursors, but they process into the same mature miRNA. The promoters of these two genes are both embedded in $\mathrm{CpG}$ islands. The covalent addition of methyl group occurs on the number 5 carbon of the pyrimidine ring of cytosine within the context of the CpG dinucleotide [10]. As genetic alterations, the epigenetic DNA changes have been shown to be involved in tumorigenesis. It has been shown that changes in DNA methylation of promoter associated $\mathrm{CpG}$ islands are one of the important epigenetic mechanisms leading to dysregulation of miRNAs in cancer [11]. Recent advances in our knowledge of DNA methylation underlie many clinical applications including the development of molecular markers for detection, prediction of prognosis, and cancer treatment outcomes. 
Several studies have been carried out on methylation of the promoter of miR-125b in various cancers, suggesting that the hypermethylation of promoter $\mathrm{CpG}$ islands is correlated with the downregulation of miR-125b [12-14]. Since reported data showed that the expression of miR-125b was deregulated in gastric carcinoma, in this study the methylation status of $\mathrm{CpG}$ islands located in promoter of miR-125b1 in gastric carcinoma tissues and normal gastric tissues, as a possible mechanism in regulating miR-125b expression, are examined. To this purpose, we performed methylationspecific polymerase chain reaction (MS-PCR) to evaluate methylation pattern of miR-125b1 promoter and quantitative real-time polymerase chain reaction (qRT-PCR) to determine the RNA expression changes in GC and normal tissues. To the best of our knowledge, no miR-125b1 analyses have been published on gastric tissue in the context of gastric adenocarcinoma.

\section{Patients and methods}

Sampling. A total of 285 gastric tissue specimens were obtained from surgical resection or endoscopic biopsy at Ghaem international hospital and private gastroenterology clinic from June 2016 to April 2018. 110 cases were all newly diagnosed and histopathologically confirmed gastric adenocarcinoma. The exclusion criteria were as follows: patients who had previously been diagnosed with cancer; patients who had received radiotherapy or chemotherapy. Patients' clinicopathological information such as, tumor size, location, staging, type was obtained. Moreover, 175 (age, sex and ethnicity matched) healthy controls were selected. Exclusion criteria for controls included history of personal or familial

Table 1. Primers used for Nested-MSP analysis.

\begin{tabular}{|c|c|c|c|}
\hline $\begin{array}{l}\text { Primer } \\
\text { designation }\end{array}$ & Sequence $\left(5^{\prime} \rightarrow 3^{\prime}\right)$ & $\begin{array}{l}\operatorname{Tm} \\
\left({ }^{\circ} \mathrm{C}\right)\end{array}$ & $\begin{array}{c}\text { PCR } \\
\text { length } \\
\text { (bp) }\end{array}$ \\
\hline OuterF & GGAGAAGAAATATTTGTAAAAGGG & \multirow{2}{*}{53} & \multirow{2}{*}{858} \\
\hline OuterR & TCTTTCССССАAАACAAATATAC & & \\
\hline InnerMF & TGGTGTATCGTTTTTTGTTTTC & \multirow{2}{*}{62} & \multirow{2}{*}{162} \\
\hline InnerMR & ACCCATTCGAAACGAAAC & & \\
\hline InnerUF & ATTTGGTGTATTGTTTTTTGTTTTT & \multirow{2}{*}{62} & \multirow{2}{*}{168} \\
\hline InnerUR & СТСАСССАТТСААААСАААAC & & \\
\hline
\end{tabular}

$\mathrm{F}=$ forward $\mathrm{R}=$ reverse; $\mathrm{M}=$ methylated primer; $\mathrm{U}=$ unmethylated primer

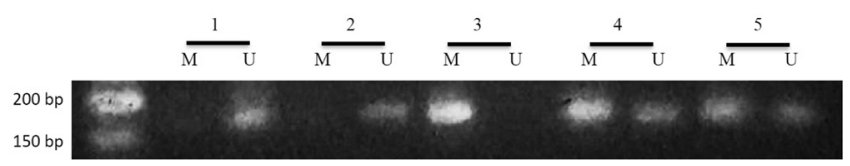

Figure 1. Gel electrophoresis of the final Nested-MSP products. The presence of a band under the $U$ or $M$ lanes indicates unmethylated or methylated DNA sequences. malignancy and other serious diseases. Controls were also genetically unrelated to the cases. Stomach tissue samples were immediately stored in liquid nitrogen for subsequent analysis. All subjects were interviewed using a structured questionnaire to obtain information on demographic factors and health characteristics. All specimens were evaluated by at least one pathologist, who confirmed the diagnoses from hematoxylin- and eosin-stained tissue sections. Written informed consent was obtained from all the subjects. This study was conducted in accordance with the principles of the 2013 Declaration of Helsinki.

DNA extraction and bisulfite conversion. Genomic DNA from normal gastric mucosa and GC specimen was extracted using the High Pure PCR Template Preparation Kit (Roche, Germany) according to the manufacturer's instructions. Yield and purity of extracted DNA was assessed using a Nanodrop UV-Vis spectrophotometer at 260 and $280 \mathrm{~nm}$ (Thermo Fisher Scientific, USA).

About $2 \mu \mathrm{g}$ of extracted genomic DNA was modified with sodium bisulfite using the EpiTect Bisulfite Kit (Qiagen, Germany) in accordance with the manufacturer's instructions. In this reaction, methylated cytosine is protected and unmethylated cytosine is changed to the uracil. After desulfonation, the DNA was purified on silica-membrane columns to a final volume of $20 \mu \mathrm{l}$. The modified DNA was stored at $-20^{\circ} \mathrm{C}$ until further analysis.

Methylation specific PCR. We analyzed the methylation status of the one $\mathrm{CpG}$ site in promoter region of miR-125b1 in gastric adenocarcinoma cases and controls by nested methylation specific PCR (Nested-MSP), which consists of two-step PCR amplifications. The sequences of specific primers were designed based on relevant DNA sequences available in the NCBI GenBank database (http://www.ncbi.nlm.nih.gov/ genbank) using Methprimer software (http://www.urogene. org/methprimer/) [15]. Details of the primers are shown in Table 1. Primers were synthesized by MWG-Biotech (Ebersberg, Germany). The PCR reaction contained $50 \mathrm{ng}$ of bisulfite-treated DNA, 1.5 pmol of each primers pair and $14 \mu \mathrm{l}$ PCR Master Mix (2X) (Thermo Fisher Scientific, USA) in a total volume of $25 \mu$ l. The PCR was performed in a 96-well mini PCR System Thermal cycler (BioRad, USA). The thermal amplification cycling was performed at $95^{\circ} \mathrm{C}$ for $5 \mathrm{~min}$, followed by thirty-five cycles consisting of a denaturing step for $40 \mathrm{~s}$ at $94^{\circ} \mathrm{C}$, an annealing step for $40 \mathrm{~s}$ at $53^{\circ} \mathrm{C}$ (first round) or $62^{\circ} \mathrm{C}$ (second round), extension step for $40 \mathrm{~s}$ at $72^{\circ} \mathrm{C}$ and final extension at $72^{\circ} \mathrm{C}$ for $5 \mathrm{~min}$. The EpiTect PCR Control DNA (Qiagen, Germany) was used for methylated and unmethylated controls. An amount of $5 \mu \mathrm{l}$ of each amplified products was analyzed using $2 \%$ agarose gel electrophoresis and visualized under ultraviolet light with Gel-Red staining. Analysis was performed without knowing each subject's case or control status. All the PCR products were of the expected length (Figure 1). About 10\% of randomly selected samples were repeated independently to verify the results. 
Evaluation of miR-125b1 expression. Total RNA was isolated from gastric tissue with TRIzol reagent (Invitrogen, USA) following the manufacturer's instructions. The purity and concentration of total RNA were assessed with a Nanodrop UV-Vis spectrophotometer at 260 and $280 \mathrm{~nm}$. The integrity of the RNA samples was determined by $2.0 \%$ agarose gel electrophoresis. cDNA was produced using the PrimeScript 1st Strand cDNA Synthesis Kit (Takahara, Japan) according to the manufacturer's protocol. cDNA was stored at $-20^{\circ} \mathrm{C}$ until used.

Quantitative PCR. The $\mathrm{qPCR}$ was performed using Green Hot Master Mix (BioRon, Germany) on a Roche lightcycler 96 Instrument (Roche Molecular Systems). The sequences of miR-125b1 gene primers were as follows: miR-125b, sense: 5'-GGATTCCCTGAGACCCTAAC-3' and miR-125b antisense: 5'-GTGCAGGGTCCGAGGT-3'. Reactions were conducted at $95^{\circ} \mathrm{C}$ for $3 \mathrm{~min}$ as an initial denaturation, followed by 40 cycles at $95^{\circ} \mathrm{C}$ (denaturation step) for $15 \mathrm{~s}, 60^{\circ} \mathrm{C}$ for $60 \mathrm{~s}$ (combined annealing/extension step with fluorescence data collection) [16]. Each run was completed with a melting curve analysis. In the negative control group, qRT-PCR was performed using water instead of cDNA as the template. Quantitative measurements were performed in triplicate and relative expression was measured using comparative $\mathrm{Ct}$ method $\left(2^{-\Delta \Delta \mathrm{Ct}}\right)$ and normalized to U6 snRNA as internal control.

Analysis of promoter sequence on transcription factors binding. The promoter nucleotide sequence data on miR-125b1 gene was retrieved from Entrez Gene on National Centre for Biotechnology Information (NCBI) website. Promo (version 3.0.2), an online web-based tool, (http:// alggen.lsi.upc.es/cgi-bin/promo-v3/promo/) [17] was used for prediction of transcription factor binding sites in DNA sequences.

Statistical analysis. The $\chi^{2}$ test was used to analyze the correlation between miR-125b methylation and clinicopathological features. The quantity of gene expression was analyzed as described by Livak and Schmittgen [18]. The significance of association was assessed by odds ratios (OR) with confidence intervals (CI) of 95\%. All statistical analyses were performed with SPSS statistical package, version 20.0. (SPSS Inc., Chicago, IL, USA). For all statistical analysis, $\mathrm{p}<0.05$ was considered to be statistically significant.

\section{Results}

The main characteristics and demographic descriptions of the study participants are presented in Table 2. In total, 285 participants were identified in the study, including 110 patients with gastric adenocarcinoma and 175 controls. Among the 110 subjects studied with GC, 78 (70.9\%) were male and $32(29 \%)$ were female. Considering the control group, $74.8 \%$ (131) were male and 25\% (44) were female. Briefly, there was no significant differences in the distributions of age $(p=0.53)$ and sex $(p=0.74)$ between the cases
Table 2. Correlation between miR-125b1 promoter methylation and clinicopathological characteristics of cases.

\begin{tabular}{lcccc}
\hline $\begin{array}{l}\text { Clinicopathological } \\
\text { parameters }\end{array}$ & $\begin{array}{c}\text { Methylated } \\
\text { Allele } \\
\mathbf{N}(\%)\end{array}$ & $\begin{array}{c}\text { Unmethyl- } \\
\text { ated Allele } \\
\mathbf{N}(\%)\end{array}$ & $\chi^{2}$ & p-value $^{\mathrm{b}}$ \\
\hline Sex & $11(17.2)$ & $53(83.8)$ & 1.34 & 0.24 \\
$\quad$ Female & $38(24.3)$ & $118(75.7)$ & & \\
$\quad$ Male & & & & \\
Age & $13(25)$ & $39(75)$ & 0.24 & 0.61 \\
$\quad<50$ & $36(21.4)$ & $132(78.6)$ & & \\
$\quad \geq 50$ & & & & \\
Location & $8(11.8)$ & $60(88.2)$ & 6.27 & $\mathbf{0 . 0 1}$ \\
$\quad$ Cardia & $41(27)$ & $111(73)$ & & \\
$\quad$ Noncardia & & & & \\
Type & $37(22.6)$ & $127(77.4)$ & 0.03 & 0.86 \\
$\quad$ Intestinal & $12(21.4)$ & $44(78.6)$ & & \\
$\quad$ Diffuse & & & & \\
Stage & $5(8.6)$ & $53(91.4)$ & 8.47 & $\mathbf{0 . 0 0 3}$ \\
I-II & $44(27.2)$ & $118(72.8)$ & & \\
III-VI & & & \\
\hline
\end{tabular}

according to Lauren's classification; boldfaced value indicates a significant difference at the $5 \%$ level.

and controls as suggested by the chi square tests. Regarding TNM stage according to the $7^{\text {th }}$ Edition of the American Joint Committee on Cancer, 29 (26.3\%), and 81 (73.6\%) patients classified as stage I-II, and III-IV, respectively. Eighty-four (76.3\%) patients had intestinal type of GC, according to Lauren's classification [19].

The methylation status of miR-125b1 promoter was examined by methylation specific polymerase chain reaction (MS-PCR). We investigated a CpG island upstream of the miR-125b1 transcriptional start site, from -373 to $-603 \mathrm{bp}$ (Figure 2). MiR-125b1 promoter were homozygously methylated in 21 (19\%) cases but was not seen in healthy controls. The frequency of methylated allele was $24.5 \%$ in GC cases but only $10 \%$ in normal tissues. Statistically significant correlation between $\mathrm{CpG}$ dinucleotide methylation of miR-125b1 promoter and increased risk of gastric adenocarcinoma was observed $(\mathrm{OR}=2.57$; 95\%CI 1.60-4.13; $\mathrm{p}=0.0001)$.

To examine the association between methylation status of miR-125b1 and clinicopathological characteristics of GC, the cases were stratified into subgroups according to sex, age, tumor location, type and stages. The results are presented in Table 2. A significant relationship was found between tumor location and methylation status of miR-125b1 $(p=0.02)$. The results of our study also demonstrated a significantly methylated promoter in higher stage of gastric carcinoma than in stage I-III $(\mathrm{p}=0.009)$. However, there was no correlations between promoter methylation of miR-125b1 and type of tumor, sex and age ( $\mathrm{p}>0.05)$.

Downregulation of miR-125b1 transcript. We evaluated whether miR-125b1 expression level is related to GC (Figure 3). The qRT-PCR analysis revealed that the relative level of miR-125b1 expression was significantly lower in cancerous tissues compared to normal specimens $(0.84 \pm 0.18$ 


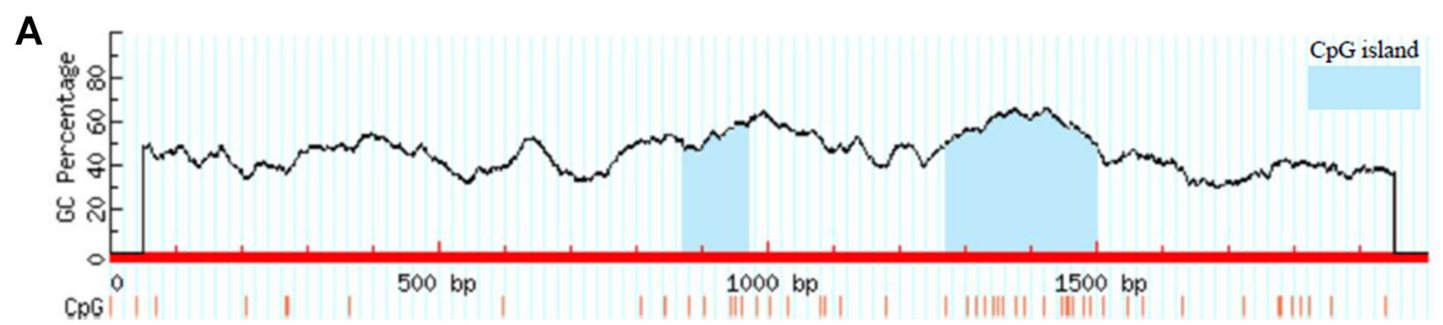

B

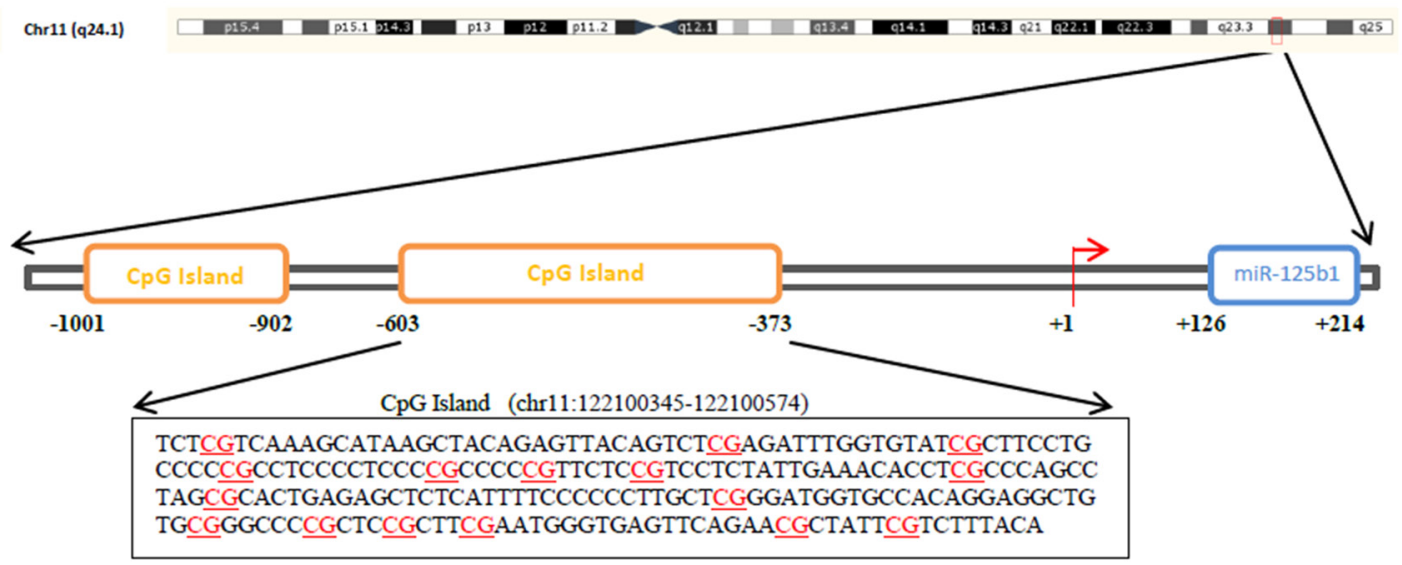

Figure 2. A) Two CpG islands were predicted by using Methprimer software. B) Schematic representation of the CpG islands location within miR$125 \mathrm{~b} 1$ promoter.
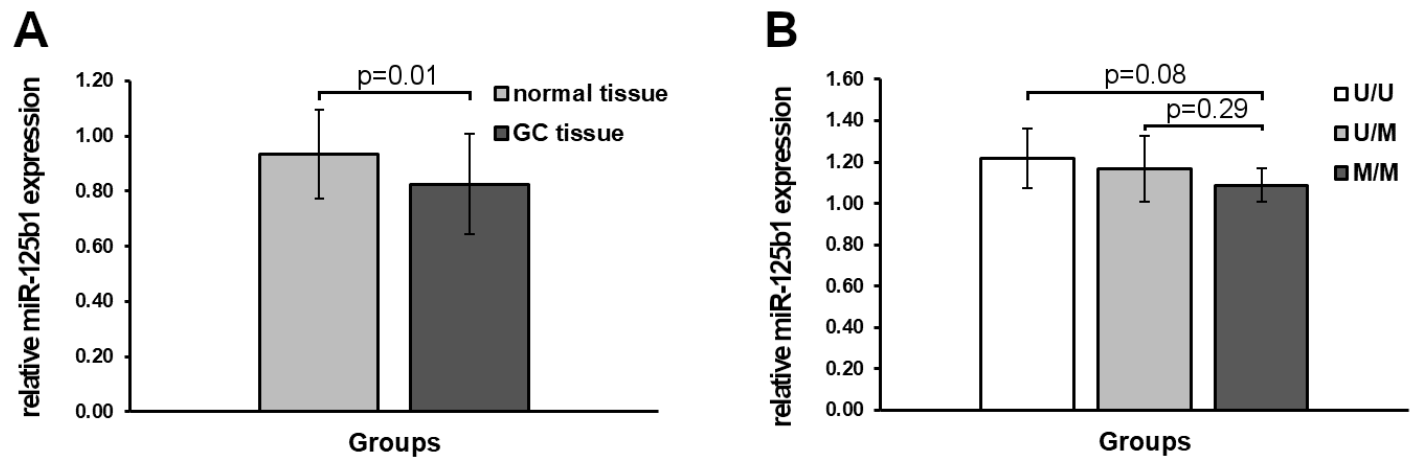

Figure 3. A) Expression level of miR-125b1 in GC patients and controls. B) Comparison of miR-125b1 relative expression among patients with different methylation status. Data are expressed as means $\pm S D, M=$ methylated, $U=$ unmethylated

vs. 0.95 $\pm 0.16, \mathrm{p}=0.01)$. However, there were no apparent differences in miR-125b1 transcription level among patients with methylated, hemi-methylated and un-methylated CpG ( $\mathrm{p}>0.05)$.

In silico analysis. Promo program for in silico analysis revealed that the $\mathrm{CpG}$ located within promoter region of miR-125b1 gene can be a potential location for remarkable transcription binding factors such as WT1, E2F-1, ETF, and MAZ. The outcome of the promo server has been shown in Suppl. Figure S1. Based on our analysis, we hypothesized that the methylated promoter could reduce the affinity of transcription factors to miR-125b1 coding DNA binding. This may influence the miR-125b1 expression level.

\section{Discussion}

This is the first study that demonstrates the effects of miR-125b1 methylation status on gastric adenocarcinoma risk. Methylation of miR-125b1 promoter was observed in $44.5 \%$ of cases and $6.3 \%$ healthy controls. We also found that 
the expression of miR-125b1 was markedly downregulated in the gastric tumor tissues compare to normal stomach mucosa. Furthermore, the promoter methylation significantly correlated with tumor stage, and location, therefore suggesting that the methylation level may have a prognostic value.

MiR-125b has been reported to suppre ss cancer cell proliferation, and invasion by targeting MCL1 [9]. It is downregulated in some cancers, including GC $[9,16]$, prostate cancer [20], breast cancer [21] and liver cancer [22]. Recently, Zhang et al. found that miR-125b was significantly downregulated in GC tissues and various cell lines. They also suggested that miR-125b plays a pivotal role in GC which may provide a foundation for its application in clinical diagnosis as well as treatment [16]. Conversely, in three different experiments, an upregulation of miR-125b was reported in GC compare to normal tissue $[8,23,24]$.

Modulation of miR-125b expression by epigenetic silencing was found in isoniazid-induced liver injury, resulting in enhancing STAT3 oncogene expression [25]. MiR-125b1 has also been shown to be downregulated in breast cancer samples using MS-PCR method [26]. Furthermore, the authors suggested that miR-125b1 promoter hypermethylation could be a potential biomarker of breast cancer metastasis.

It has been suggested that a downregulation of miR-125b1 in breast, ovarian and cervical cancers is correlated with promoter methylation, repressive histone marks (such as $\mathrm{H} 3 \mathrm{~K} 9 \mathrm{me} 3$ and $\mathrm{H} 3 \mathrm{~K} 27 \mathrm{me} 3$ ) and loss of CCCTC-binding factor (CTCF) binding at the promoter [12]. Chen et al. demonstrated that miR-125b promoter hypermethylation leads to reduction of expression of this miRNA in colorectal cancer, which is associated with the progression of this cancer [14].

It is known that miRNAs play an important role in the onset and progression of cancer by targeting tumor suppressor genes and oncogenes [27]. The aberrant expression of miR-125b1 is associated with proliferation, apoptosis, invasiveness and metastasis in cancer cells $[9,28]$. It has been previously determined that DNA methylation at the CpG sites in promoters can affect the binding of transcription factors to their binding sites $[29,30]$. Since it has been observed in our study that the promoter methylation of miR-125b1 is associated to its expression, we hypothesize that the methylation of $\mathrm{CpG}$ sites in the promoter of the miR-125b1 gene may prevent the binding of the transcription factors to their binding sites, resulting in reduction of its transcription.

We acknowledged that there were several limitations in this study. Firstly, the sample size may limit the statistical power of our study. Second, environmental risk factors including diet habits, $H$. pylori infection were not available for further analysis, which should be investigated in future studies. Finally, to evaluate the effects of miR-125b1 methylation on GC risk, further studies which include more CpG islands on miR-125b1 would be required. In addition, further investigation of the mechanism of miR-125b1 downregula- tion may improve the understanding of the role played by miRNAs in gastric carcinogenesis.

In conclusion, this is a first report of miR-125b1 promoter methylation in GC. The hypermethylation of miR-125b1 in GC suggests that it may act as a tumor suppressor in response to gastric tumorigenesis which should be a therapeutic strategy for the treatment of GC. We also predicted the impact of promoter methylation on transcription factor binding. Whether this modification involves any differential change in miR-125b binding to its transcription factors, needs to be further studied.

Acknowledgements: This study was supported partly by University of Guilan. The authors thank to all participants of the study.

\section{References}

[1] FERLAY J, STELIAROVA-FOUCHER E, LORTET-TIEULENT J, ROSSO S, COEBERGH J-WW et al. Cancer incidence and mortality patterns in Europe: estimates for 40 countries in 2012. Eur J Cancer 2013; 49: 1374-1403. https:// doi.org/10.1016/j.ejca.2012.12.027

[2] RUGGE M, FASSAN M, GRAHAM DY. Epidemiology of gastric cancer. pp. 23-34. In: VE Strong (Eds.). Gastric Cancer. Principles and Practice. Springer, 2015, p. 333. ISBN ISBN 978-3-319-15826-9

[3] BELAIR C, DARFEUILLE F, STAEDEL C. Helicobacter pylori and gastric cancer: possible role of microRNAs in this intimate relationship. Clin Microbiol Infect 2009; 15: 806-812. https://doi.org/10.1111/j.1469-0691.2009.02960.x

[4] PAN H-W, LI S-C, TSAI K-W. MicroRNA dysregulation in gastric cancer. Curr Pharm Des 2013; 19: 1273-1284. https:// doi.org/10.2174/138161213804805621

[5] UEDA T, VOLINIA S, OKUMURA H, SHIMIZU M, TACCIOLI C et al. Relation between microRNA expression and progression and prognosis of gastric cancer: a microRNA expression analysis. Lancet Oncol 2010; 11: 136-146. https:// doi.org/10.1016/S1470-2045(09)70343-2

[6] PENG Y, CROCE CM. The role of MicroRNAs in human cancer. Signal Transduct Target Ther 2016; 1: 15004. https:// doi.org/10.1038/sigtrans.2015.4

[7] BARTEL DP. MicroRNAs: genomics, biogenesis, mechanism, and function. Cell 2004; 116: 281-297. https://doi. org/10.1016/S0092-8674(04)00045-5

[8] WU JG, WANG JJ, JIANG X, LAN JP, HE XJ et al. MiR-125b promotes cell migration and invasion by targeting PPP1CA$\mathrm{Rb}$ signal pathways in gastric cancer, resulting in a poor prognosis. Gastric Cancer 2015; 18: 729-739. https://doi. org/10.1007/s10120-014-0421-8

[9] WU S, LIU F, XIE L, PENG Y, LV X et al. miR-125b Suppresses Proliferation and Invasion by Targeting MCL1 in Gastric Cancer. Biomed Res Int 2015; 2015: 365273. https:// doi.org/10.1155/2015/365273

[10] MOORE LD, LE T, FAN G. DNA methylation and its basic function. Neuropsychopharmacology 2013; 38: 23-38. https://doi.org/10.1038/npp.2012 
[11] SUZUKI H, MARUYAMA R, YAMAMOTO E, KAI M. DNA methylation and microRNA dysregulation in cancer. Mol Oncol 2012; 6: 567-578. https://doi.org/10.1016/j. molonc.2012.07.007

[12] SOTO-REYES E, GONZALEZ-BARRIOS R, CISNEROSSOBERANIS F, HERRERA-GOEPFERT R, PEREZ V et al. Disruption of CTCF at the miR-125b1 locus in gynecological cancers. BMC Cancer 2012; 12: 40. https://doi. org/10.1186/1471-2407-12-40

[13] ZHANG Y, YAN LX, WU QN, DU ZM, CHEN J et al. miR$125 \mathrm{~b}$ is methylated and functions as a tumor suppressor by regulating the ETS1 proto-oncogene in human invasive breast cancer. Cancer Res 2011; 71: 3552-3562. https://doi. org/10.1158/0008-5472.CAN-10-2435

[14] CHEN H, XU Z. Hypermethylation-associated silencing of miR-125a and miR-125b: a potential marker in colorectal cancer. Dis Markers 2015; 2015: 345080. https://doi. org/10.1155/2015/345080

[15] LI L-C, DAHIYA R. MethPrimer: designing primers for methylation PCRs. Bioinformatics 2002; 18: 1427-1431.

[16] ZHANG X, YAO J, GUO K, HUANG H, HUAI S et al. The functional mechanism of miR-125b in gastric cancer and its effect on the chemosensitivity of cisplatin. Oncotarget 2017; 9: 2105-2119. https://doi.org/10.18632/oncotarget.23249

[17] FARRE D, ROSET R, HUERTA M, ADSUARA JE, ROSELLO $L$ et al. Identification of patterns in biological sequences at the ALGGEN server: PROMO and MALGEN. Nucleic Acids Res 2003; 31: 3651-3653.

[18] LIVAK KJ, SCHMITTGEN TD. Analysis of relative gene expression data using real-time quantitative PCR and the 2(-Delta Delta C(T)) method. Methods 2001; 25: 402-408. https://doi.org/10.1006/meth.2001.1262

[19] LAUREN P. The two histological main types of gastric carcinoma: diffuse and so-called intestinal-type carcinoma: an attempt at a histo-clinical classification. Acta Pathol Microbiol Scand 1965; 64: 31-49.

[20] WALTER BA, VALERA VA, PINTO PA, MERINO MJ. Comprehensive microRNA profiling of prostate cancer. J Cancer 2013; 4: 350-357. https://doi.org/10.7150/jca.6394

[21] FELICIANO A, CASTELLVI J, ARTERO-CASTRO A, LEAL JA, ROMAGOSA C et al. miR-125b acts as a tumor suppressor in breast tumorigenesis via its novel direct targets ENPEP, CK2- $\alpha$, CCNJ, and MEGF9. PLoS One 2013; 8: e76247. https://doi.org/10.1371/journal.pone.0076247
[22] LIANG L, WONG C-M, YING Q, FAN DN-Y, HUANG S et al. MicroRNA-125b suppressesed human liver cancer cell proliferation and metastasis by directly targeting oncogene LIN28B 2. Hepatology 2010; 52: 1731-1740. https://doi. org/10.1002/hep.23904

[23] YANG ZX, LU CY, YANG YL, DOU KF, TAO KS. MicroRNA-125b expression in gastric adenocarcinoma and its effect on the proliferation of gastric cancer cells. Mol Med Rep 2013; 7: 229-232. https://doi.org/10.3892/mmr.2012

[24] CHANG S, HE S, QIU G, LU J, WANG J et al. MicroRNA$125 \mathrm{~b}$ promotes invasion and metastasis of gastric cancer by targeting STARD13 and NEU1. Tumour Biol 2016; 37: 12141-12151. https://doi.org/10.1007/s13277-016-5094-y

[25] LI Y, REN Q, ZHU L, LI Y, LI J et al. Involvement of methylation of MicroRNA-122, -125b and -106b in regulation of Cyclin G1, CAT-1 and STAT3 target genes in isoniazid-induced liver injury. BMC Pharmacol Toxicol 2018; 19: 11. https:// doi.org/10.1186/s40360-018-0201-x

[26] PRONINA I V, LOGINOV VI, BURDENNYY AM, FRIDMAN M V, SENCHENKO VN et al. DNA methylation contributes to deregulation of 12 cancer-associated microRNAs and breast cancer progression. Gene 2017; 604: 1-8. https:// doi.org/10.1016/j.gene.2016.12.018

[27] GARZON R, FABBRI M, CIMMINO A, CALIN GA, CROCE CM. MicroRNA expression and function in cancer. Trends Mol Med 2006; 12: 580-587. https://doi.org/10.1016/j.molmed.2006.10.006

[28] LE MT, TEH C, SHYH-CHANG N, XIE H, ZHOU B et al. MicroRNA-125b is a novel negative regulator of $\mathrm{p} 53$. Genes Dev 2009; 23: 862-876. https://doi.org/10.1101/gad.1767609

[29] PERINI G, DIOLAITI D, PORRO A, DELLA VALLE G. In vivo transcriptional regulation of N-Myc target genes is controlled by E-box methylation. Proc Natl Acad Sci U S A 2005; 102: 12117-12122. https://doi.org/10.1073/pnas.0409097102

[30] KIM J, KOLLHOFF A, BERGMANN A, STUBBS L. Methylation-sensitive binding of transcription factor YY1 to an insulator sequence within the paternally expressed imprinted gene, Peg3. Hum Mol Genet 2003; 12: 233-245. 